\title{
SABER SENSÍVEL E ACUIDADE CORPORAL: METODOLOGIA DE ENSINO DE DANÇA A PARTIR DE UM ES- TUDO COM ESTUDANTES CEGOS
}

\section{THE SENSITIVE KNOWLEDGE AND BODY ACUITY: A METHODOLOGICAL PROPOSAL FOR TEACHING OF DANCE OF DANCE FROM A STUDY OF BLIND PEOPLE}

DOI: http://dx.doi.org/10.5965/1984317815042019148

\author{
Marcia Almeida \\ Universidade de Brasília \\ mars.almeida@yahoo.com.br
}

\section{RESUMO}

Este estudo desenvolveu-se entre 1994 e 1995 em uma escola da rede pública de ensino em Brasília, Distrito Federal. Isto foi consequente a necessidade de ensinar dança a pessoas que não enxergavam e não tinham o conhecimento básico para esta disciplina. Teve como objetivo proporcionar aos estudantes o que hoje eu denomino como acuidade corporal, que é uma metodologia de sensibilização e reflexão dos movimentos corporais aplicados à dança, para a partir desse conhecimento sensível, os estudantes adquirirem a autonomia poética para se expressarem através da arte coreográfica. Para a reflexão e criação no ensino da dança a minha opção teórico-metodológica fundamentou-se na proposta de Laban, quando trabalho o corpo no espaço utilizando as qualidades do movimento, peso/força, fluência, tempo e espaço; nos ensaios para o sensível proposto por Lygia Clark; estudos do corpo proposto MerleauPonty, Michael Henry e Marcel Mauss; meu conhecimento em anatomia, cinesiologia, biomecânica e sobretudo em dança. Este estudo resultou em uma metodologia para o ensino da dança, primeiramente para estudantes cegos e surdos e posteriormente expandido para dançarinos profissionais, estudantes de graduação em dança e em teatro.

Palavras-chave: Saber-sensível. Acuidade-corporal. Metodologia. Arte-coreográfica.

\begin{abstract}
This study was conductedbetween 1994 and 1995 in a public school system in Brasília, Federal District. This was consequent on the need to teach dance to people who did not see and did not have the basic knowledge for this discipline. It aimed to provide students with what I now call body acuity, which is a methodology of sensitization and reflection of the body movements applied to dance, from this sensitive knowledge, students acquire poetic autonomy to express themselves through choreographic art. For reflection and creation for dance teaching, my theoretical-methodological option was based, in Laban's proposal, when I work the body in space using the qualities of movement, weight / strength, fluency, time and space; in the trials for the sensitive proposed by Lygia Clark; studies of the proposed body Merleau-Ponty, Michael Henry and Marcel Mauss; my knowledge in anatomy, kinesiology, biomechanics and especially in dance. This study resulted in a methodology for teaching dance, primarily for blind and deaf students and later expanded to professional dancers, graduate students in dance and theater.
\end{abstract}

Keywords: Sensitive-knowledge. Body-acuity. Methodology. Choreographic-art. 


\section{INTRODUÇÃO}

Este estudo surgiu quando em 1994 eu trabalhei na rede pública de ensinos fundamental e médio em Brasília, DF. Fui trabalhar em uma escola especializada no atendimento de estudantes cegos, Centro de Ensino para Deficientes Visuais - CEDV. O objetivo era ensinar-lhes a dançar. Trabalhei com três turmas, uma com três crianças na faixa etária de 5 anos, outra com três estudantes entre 11 e 15 anos, e uma terceira turma com quatro adultos em idades variadas, totalizando 10 estudantes. Nesta situação o método aqui proposto poderia permanecer carente de experimentação. Mas posteriormente também o apliquei com sucesso no ensino de dança contemporânea para pessoas que enxergam.

Para a solução de dúvidas eventuais é importante esclarecer que na apreciação deste artigo os leitores entenderão como nenhuma repetição é necessária ao aprendizado estético, porque o método aqui proposto não procede por repetição de técnica pré-concebida, e sim por conceito de percepção do corpo e do movimento: não é repetição mecânica e sim experimentação orgânica. O tempo de aprendizado foi menor do que um ano letivo, sendo apenas uma aula por semana de 50 minutos. Foram três meses de composição e ensaio coreográfico, cujo espetáculo foi apresentado em novembro de 1994. Adultos se recusaram a seguir a proposta pedagógica: queriam cópia de movimentos e não aceitaram criar seus próprios movimentos como pretende o método proposto. Não foi incompreensão didática, e sim rejeição do conceito de criação artística.

Antes de nós adentrarmos em como ocorreu este processo eu preciso sublinhar um fator importante que marca a minha carreira pedagógica. Fiz minha formação acadêmica em dança na Sorbonne-Paris 4, e isso foi determinante para a condução e resultado desta pesquisa. Pois no período de minha graduação durante a década de 1980 foram introduzidos estudos somáticos nas universidades que ofereciam graduação em dança. Naquela época a nossa atual "educação somática" era conhecida na França como "terapia para dançarinos". 
Eu tive aulas nesse programa de formação ministradas por Johanne Wolson. Esta professora foi orientada por Françoise Mézières, que estudou o movimento através da percepção corporal.Eu também participava nos finais de semana de diversos estágios de formação intensiva tais como: Ideokinesis de Sweigard, Técnica Alexander o Método Feldenkrais, e os princípios fundamentais de Bartenieff, classificados por Batson (2010) como as quatro técnicas maiores.

Outro ponto importante a colocar em destaque sobre minha formação é que a Sorbonne valoriza o conhecimento histórico e o aprofundamento teórico nas ideias já produzidas anteriormente. A partir do estudo sobre a produção estética já existente, estudantes têm incentivo para propor inovações. No curso de dança que fiz durante a década de 1980, nós estudantes éramos direcionadas para a autonomia poética, exceto em disciplinas ligadas a formas tradicionais de dança (tais como a dança clássica europeia, indiana, etc.) que têm um modelo a ser seguido.Nesse período Pina Bausch já influenciava no modo de trabalhar a dança, através de estímulos e reações de movimentos corporais considerados como se fossem o diálogo de "perguntas" e "respostas" de acordo com Servos (2001) e Endicott (1999).Em relação às formas expressivas, Bausch não trabalhava seu método com base em regras e modelos prédefinidos de movimento.Foi com estas influências na formação adquirida em meus estudos superiores que eu entrei como professora na rede pública de ensino do Distrito Federal.

Quando comecei a trabalhar com estudantes cegos a coordenação da escola estava orientada para esperar de mim, o ensino de passos formatados para apresentar aos pais e mães durante festividades escolares. Mas eu não poderia corresponder a estes anseios sem contrariar minha formação, porque 0 ensino da dança que cursei, valorizou mais o despertar do potencial criativo de estudantes e menos a repetição de passos dados por coreógrafos.Considero que ensinar passos já elaborados corresponde analogamente nas artes visuais, a ensinar o desenho a partir de formas já pontilhadas. Ou pintar dentro dos limites de uma figura já desenhada com cores já decididas por outra pessoa que não seja o artista. Isso seria ensinar as pessoas a se modelarem de forma bas- 
tante conformista e acrítica aos padrões pré-estabelecidos que já são tendenciosos. A meu ver a função do ensino em arte não é de repetição de modelos estéticos, e sim o despertar das autonomias crítica e poética.

Marcel Mauss (1936) considerou que hábitos e técnicas corporais são adquiridos desde a tenra idade. Esta aquisição de corporeidade é um processo de construção da pessoa na sociedade cuja continuidade com alguma tradição cultural, se dá de acordo com o prestígio que as crianças concedem às pessoas adultas que admiram ter como modelo. Bourdieu (1986) acrescentou que tanto crianças quanto adultos observam as atitudes das pessoas que elas prestigiam, para mimese moral e aprendizado ético de como agir no mundo.Eu já havia a experiência de trabalhar com adultos que nunca dançaram em uma ocasião anterior a esta do ensino de dança para estudantes cegos. Experiência que adquiri durante estágio para a licenciatura. Usando o conhecimento que obtive na minha formação eu consegui conduzi-los nesta ocasião didática a se expressarem por meio da dança. Porém o novo desafio pedagógico exigia observar que a metodologia para o ensino de pessoas que enxergam e nunca dançaram, é muito diferente desta para ensinar pessoas que nunca dançaram e não enxergam. Com o primeiro grupo é possível demonstrar pelo próprio gesto um movimento para que eles busquem visualmente a sensação corporal em si mesmos. Com estudantes cegos isso é impossível. Eu me questionava como fazer esses estudantes adquirirem a percepção desta autonomia criativa da dança sem o recurso sensorial da visão.

No caso de estudantes cegos faltava um aprendizado visual a partir da imitação corporal de gestos executados por outra pessoa, tal como no exemplo do salto que veremos mais adiante. Nós então deveremos com isto considerar como cegos têm dificuldades para aprender o salto. Isto quer dizer apenas que a referência do modelo visual se torna impossível ou quase, e não que a pessoa cega careça do potencial biomecânico de saltar, e menos ainda do potencial lírico de saltar por poesia. Era preciso então implementar uma proposta pedagógica, em que a aprendizagem se desse por meio de outra fonte sensorial diferente da visão. 
Adiante relatarei o resultado da pesquisa gerada por esse problema pedagógico. Minha meta foi ensinar autonomia poética para expressão em dança. $\mathrm{O}$ meu interesse é sempre ligado à prática reflexiva em artes. $\mathrm{O}$ trabalho nessa opção pedagógica produziria resultados desconhecidos e incertos. Era uma experiência didática para longo prazo, e foi uma grande oportunidade para o meu aprendizado profissional. Realizar uma pesquisa foi consequência dessa experiência, e desenvolver novas propostas pedagógicas para o trabalho da dança foi o resultado.

\section{INICIO DESSA PESQUISA SOBRE O ENSINO DA DANÇA}

A minha maneira de preparar um programa de ensino passa por quatro questionamentos: $\mathrm{O}$ que ensinar? Quem é o público alvo? Como orientar o aprendizado? Como sei que atingi meu objetivo? Como já mencionado acima eu iria ensinar autonomia poética em dança para estudantes cegos. Isto respondeu às duas primeiras questões. O difícil foi solucionar a terceira questão, para então ter condições de responder a última. Era preciso orientar a aquisição daquilo que hoje eu denomino de acuidade corporal,e que Shusterman (2007) já chamava de soma-estéticapara que estudantes cegos pudessem expressar poeticamente o que Merleau-Ponty(1966-1996)tratou enquanto fenômeno da existência: a interação do corpo com o mundo.

São várias as técnicas disponíveis para condução do aprendizado da percepção corporal. As já citadas quatro técnicas corporais maiores da educação somática (BATSON, 2010), não foram pensadas para o ensino da autonomia poética da dança. Elas se ligam muito mais à fisioterapia do que à estética É necessário que a pessoa que orienta o aprendizado em dança, faça a aplicação desta inteligência corporal adquirida com a educação somática na arte de expressar poeticamente os gestos dançados (GODAR, 1994).

Realizei um estudo baseado no conhecimento das técnicas maiores da educação somática e do método Mézières. A proposta estava voltada para um ensino de dança que atendesse às necessidades que descrevi acima. Fiz 
emergir uma metodologia para o ensino da dança inspirada em Laban, Clark, nas técnicas somáticas, nos meus conhecimentos em anatomia, biomecânica, cinesiologia e evidentemente em dança contemporânea.Eu precisava de uma forma de fazer os estudantes se perceberem como "corpo próprio"(MERLEAUPONTY, 1945, 1996). Para isto eu me utilizei da proposta de Laban segundo a qual nós trabalhamos em cena o duplo conceito de espaço no corpo e de corpo no espaço (LABAN, 1966, 2003 e 1988, 1994). Dito de outra maneira eu precisava achar uma forma para as pessoas perceberem a si mesmas e ao mundo, mas sem intervalo entre corpo e mundo. Isto é: corpo e mundo se integram e afetam um ao outro mutuamente. Ou como propôsMichel Henry $(1965,2006)$, era necessário perceber a interioridade corporal em contato com a exterioridade corporal.

Para compreender melhor isso é preciso salientar que Michel Henry considerou que a vida não pode ser vista do lado de fora, como vemos um filme na tela do cinema. A vida é sentida e experimentada pela carne em sua interioridade invisível e imanência. Ou seja é resultado da natureza do próprio ser e não uma ação externa. Para ele a vida não é uma substância universal, cega, impessoal e abstrata. Ela é necessariamente a vida pessoal e concreta pertencente a um indivíduo. A pessoa traz consigo sua própria identidade. Ela vive suas dores e alegrias sem poder compartilhar suas sensações com quem quer que seja senão intelectualmente. Também pode sensivelmente porém com dificuldadeatravés da empatia. Isso é o queMerleau-Ponty (1966; 1996) chamou de corporeidade. A experiência de uma pessoa é vivida na sua carne, ossos, vísceras e nervos. Nós precisamos levar em consideração o percurso de vida que cada pessoa trilhou para a observação do resultado técnico-motor e poético-expressivo de seus movimentos. Caminhos de pessoas diferentes podem até mesmo serem semelhantes por questões sociais como classe, gênero ou raça, mas jamais serão iguais por trajetória biográfica: cada experiência de vida é uma história pessoal.

Para o aprendizado da dança era importante trabalhar essa percepção pessoal de si mesmo e sobretudo com o corpo em movimento (SHUSTER- 
MAN, 2007; 2009). A percepção que nós temos das formas que nos envolve, não é congelada ou imóvel como estátua (MERLEAU-PONTY, 1966, 1996). As figuras de nosso redor são por nós percebidas em movimento. Nós também estamos em movimento. Entendemos que tanto a pessoa percebe a si mesma como também percebe as formas do ambiente em constante movimento. Portanto é o conhecimento prévio que temos das coisas no mundo como por exemplo uma mesa, que nos faz senti-la como um objeto estático.

Me vi motivada a propor uma metodologia de sensibilização, isto é conscientização e reflexão dos movimentos corporais aplicados à dança.O primeiro passo foi experimentar os movimentos em mim mesma. Emseguida compartilhei os princípiosdeste estudo com os estudantes cegos. Nesta ocasião de pesquisa resultou uma ideia que hoje eu chamo de acuidade corporal.

\section{ACUIDADE CORPORAL}

\subsection{Experimentos sensoriais dos movimentos}

Seguiremos uma descrição do meu estudo sobre o processo de aquisição da acuidade corporal. Trabalhei a sensibilidade pela experimentação dos detalhes de cada articulação do corpo. Passei por todas as dobradiças desde os pés até chegar na articulação do crânio com o atlas e o axis, analogamente ao ponto de vista arquitetônico na construção de uma casa em que nós começamos pela construção dos alicerces. Pois se fossem pelas paredes ou pelo telhado, obviamente faltaria a estrutura de base ou fundação. Durante a pesquisa eu experimentei e senti a implicação de todos os movimentos articulares.

É importante sublinhar que eu enfatizei o estudo das articulações ósseas ao invés das cadeias musculares. Pois entendia e ainda entendo que ao trabalhar com os músculos eu já estaria de início, trabalhando minha análise sobre uma camada mais periférica do corpo com relação aos ossos. Ao passo que dando ênfase as sensações das articulações, promoveria o contato com uma camada mais profunda do corpo. O esqueleto é um dos tecidos mais pro- 
fundos do organismo. De tal forma que o movimento articular pudesse reverberar de dentro para fora, nas vísceras, na carne e na pele, para finalmente entrar de maneira orgânica em contato com o meio ambiente. O objetivo foi promover o retorno do meio ambiente aos ossos através de uma experiência sensível do contato do próprio corpo nele mesmo e no meio ambiente. Nessa etapa eu busquei os princípios de Lygia Clark (COELLIER, 2003) que descreverei posteriormente. Agora é importante esclarecer como eu decompus neste estudo os movimentos do corpo humano.

\subsection{Decomposição dos Movimentos}

Eu focarei sobre o trabalho realizado apenas com os pés por economia de espaço no texto e tempo de atenção de leitoras. Isso basta para o propósito de neste artigo expor o meu método de ensino da dança. Mas ressalto que apliquei este mesmo procedimento em cada uma de todas as articulações do corpo. É importante também esclarecer que essa decomposição é apenas um facilitador didático dentre outros possíveis para esta proposta pedagógica.

Minha finalidade na época foi orientar os estudantes cegos para que saltassem, e posteriormente usassem esse gesto de maneira mais poética e menos funcional. O que eu chamo de gestos funcionais, são aqueles gestos referentes a uma ação, cujo objetivo é claro. Por exemplo uma corrida a fim de alcançar um ponto distante mais rapidamente. Outro exemplo é se apoiar nas pontas dos pés para alcançar mais alto. Estes e tantos outros gestos funcionais da vida cotidiana são executados para exercer uma utilidade prática e precisa. Isto não é a mesma coisa que acrescentar a estes gestos funcionais uma funcionalidade diferente, que é a função poética da linguagem corporal.

Isto já quer dizer que os gestos de uma corrida, e do se apoiar sobre as pontas dos pés, podem todos eles serem plasticamente expressivos. Mas para assim o serem, estes gestos têm muito de sua funcionalidade originariamente pragmática e utilitária, transformada obrigatoriamente em poesia. Os gestos funcionais são literais. Os gestos expressivos são metafóricos. A liturgia da expressão em dança énós conseguirmos expressão poética não somente a 
partir dos gestos funcionais como também a partir de gestos que são concebidos única e exclusivamente para os gestos dançantes. Tive que decompor os movimentos de um salto, e compartilhar essa decomposição em sala de aula pela prática da experimentação corporal de cada estudante. Analisei cada gesto funcional fragmentado da ação total do corpo, mas aqui eu descreverei como modelo de aplicação do meu método para o ensino da dança, apenas o movimento dos pés quando caminhamos para saltar. Façamos atenção para o seguinte detalhe, eu não farei a descrição dos movimentos do pé durante o voo do salto propriamente dito. Mas sim uma descrição dos gestos funcionais nos movimentos do pé durante os passos de um caminhar que precede o salto.

Pensemos sobre os gestos funcionais do pé, em suas manobras de cada passo realizado durante uma caminhada (ou corrida), que precederia o movimento de um salto. A decomposição dos gestos funcionais é aqui operada pelo estudo das ações articulares, durante a transferência de apoio em cada passo. Essa transferência é continuamente alternada passo a passo entre um pé e outro. Descreverei as fases de um só passo a partir das quatro figuras abaixo:

Figura 1 - Pé em repouso:

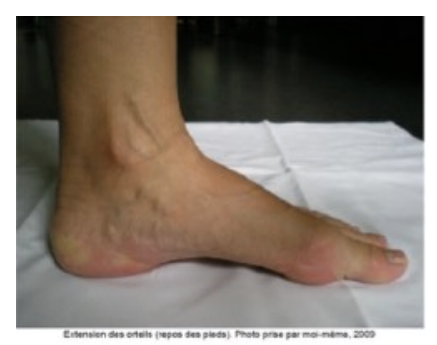

Figura 3 - flexão do tornozelo:

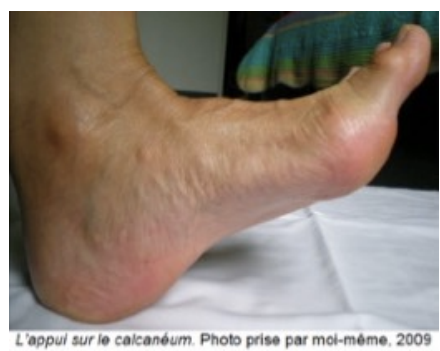

Figura 2 - apoio sobre os artelhos e extensão do pé:

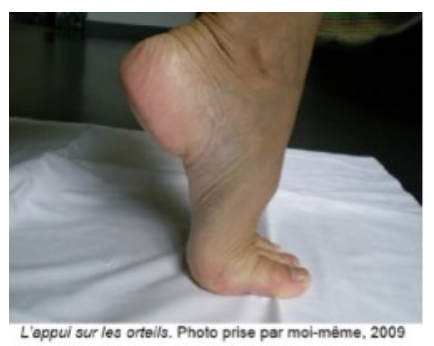

Figura 4: flexão dos artelhos (para retornar à figura A):

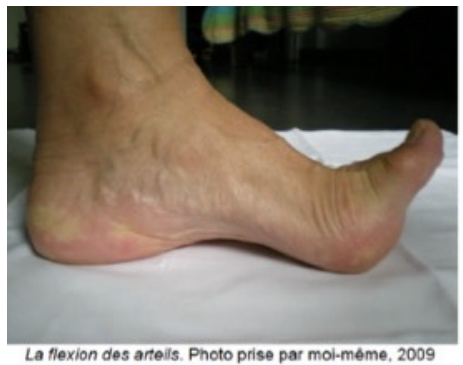


A propósito de uma análise sobre os gestos em dança, nós observaremos agora que gestos funcionais se tornam "bricolagem". Isto é o que LéviStrauss $(1962,2010)$ explicou ser um conhecimento da percepção sobre o universo, obtido pela experiência de vida prática de uma pessoa no mundo. Observemos no seguinte fragmento de texto como este antropólogo chamava nossa atenção ao arranjo de signos da bricolagem. Isto é o que constitui material de mediação entre de um lado a percepção da realidade que é constituída pela experiência sensível do corpo, e de outro lado a conceituação desta experiência que consiste na potência inteligível de sua consciência:

Ora, existe um intermediário entre a imagem e o conceito: é o signo, pois que se pode sempre defini-lo da forma inaugurada por Saussure a respeito dessa categoria particular que formam os signos linguísticos, como um elo entre uma imagem [feita de sons] e um conceito [feito de ideias], que, na união assim estabelecida [durante a fala], desempenham respectivamente os papeis de significante e significado. Assim como a imagem [sonora dos fonemas], o signo é um ser concreto, mas assemelha-se ao conceito [pensado das palavras] por seu poder referencial: um e outro [signo sonoro e conceito pensado] não se referem exclusivamente a si mesmos; além de si próprios, podem substituir outra coisa. Todavia, neste caso, o conceito possui uma capacidade [referencial] ilimitada [porque é ideia], enquanto a [capacidade referencial] do signo é limitada [porque é ruído]. A diferença e a semelhança [entre o som vocalizado e a palavra propriamente dita] ficam bem ressaltadas com o exemplo do bricoleur. Observemo-lo no trabalho: mesmo estimulado por seu projeto, seu primeiro passo prático é retrospectivo, ele deve voltar-se para um conjunto já constituído, formado por utensílios e materiais, fazer ou refazer seu inventário, enfim e sobretudo, entabular uma espécie de diálogo com ele [o inventário], para listar, antes de escolher, entre elas [a seguir], as respostas possíveis que o conjunto pode oferecer ao problema colocado. Ele [o bricoleur] interroga todos esses objetos heteróclitos que constituem seu tesouro, a fim de compreender o que cada um deles poderia "significar", contribuindo assim para definir um conjunto a ser realizado, que no final será diferente do conjunto instrumental apenas pela disposição interna das partes. [Por exemplo] Este cubo de carvalho pode [por um lado] ser um calço [de um pé de mesa], para suprir a insuficiência [com relação à altura do plano] de uma tábua de abeto [que faz a superfície estável da mesa], ou ainda [pode por outro lado ser] um soco [que faz o seu pedestal], o que permitiria realçar a aspereza e a polidez da velha madeira [pelo contraste entre o carvalho e o abeto]. Num caso [o do pedestal que faz a vez de conceito], ele será extensão [da mesa], no outro [o caso do calço do pé de mesa que faz a vez de signo], [será] matéria [prima para reconstituir a estabilidade de uma mesa manca]. Mas essas possibilidades são sempre limitadas pela história particular de cada peça e por aquilo que nela subsiste de predeterminado, devido ao 
uso original para o qual foi concebida ou pelas adaptações que sofreu em virtude de outros empregos. (LÉVI-STRAUSS, 1962, 2010: 35).

Este argumento segundo qual a bricolagem é um produto da percepção de cada pessoa sobre o universo que tem relação com sua respectiva experiência de vida, se aplica na constituição de gestos na dança pois estes são uma expressão de conhecimento pessoal sobre si mesmo e sobre o mundo. Em dança este conhecimento estético aparece pelo seu arranjo de signos gestuais, com os quais um artista da dança compõe movimentos de corpo para suas obras coreográficas.

Vimos Lévi-Strauss acima afirmar como o signo é um ser concreto e dotado de poder referencial. Elemento constituidor da percepção e do saber sensível, que é operado na associação consciente de apenas um ou também mais de um dos cinco sentidos do corpo humano: a visão, a audição, a olfação, o paladar, e o tato. Para o caso da dança nos interessam destas associações conscientes, aquelas que estejam comprometidas pelo gesto dançado, tanto no que concerne à técnica de sua liturgia quanto à inspiração de sua poesia.

No ato da dança os gestos e movimentos do corpo perdem sua funcionalidade pragmática da vida cotidiana. A paisagem anatômica do corpo, tal como concebido pelos estudos científicos, já não prevalece mais. É possível fazer uma recomposição corporal como propõe Bellmer (2006). O que era tronco na posição anatomicamente conhecida, se transforma em apoio, a planta do pé vira a parte da frente que se dá a ver ao público, e assim outras possibilidades são apresentadas por meio dos gestos dançados.Godard (1994) considerou que os gestos dançados são aqueles inacabados, que se transformam, porque são obra aberta. Dito de outra maneira, são gestos que não têm um fim, final ou finalidade. Ou seja, não são voltados para um destino ou uma função objetiva. Muito pelo contrário algumas vezes contrariam o código da linguagem estabelecida, isto é se voltam contra padrões culturais.

Eu construí meus argumentos anteriores a partir de uma análise de de- 
composição de cada conjunto articularimplicado nos gestos dos pés, quando o corpo movimenta os passos de uma corrida que precede o salto. Então pesquisei uma nova etapa após decompor cada movimento articular dos ossos da perna, para sentir como o pé impulsiona o solo na realização de um salto. Descreverei posteriormente como transpus essas experiências pessoais realizadas em mim, para serem compartilhadas com os estudantes.Uma vez compreendido pela turma durante as aulas a mecânica de cada articulação do corpo nos gestos funcionais da vida cotidiana, o próximo passo didático foi explorar o potencial poeticamente expressivos dos gestos dos pés. Isso foi feito pela combinação de diferentes possibilidades articulares transformadas em gestos dançados, que acabam bem diferentes dos gestos cotidianos tal como por exemplo o caminhar, o correr ou o saltar. Iniciei uma pesquisa onde eu experimentei possibilidades expressivas. Tendo em vista o meu princípio de ensino da arte descrito anteriormente, eu não pretendi com isto fixar possibilidades expressivas determinando fórmulas ou códigos de expressão corporal que constituem uma linguagem estética. Ao contrário estudantes desconstituiriam com a dança a linguagem pragmática dos gestos funcionais.

Para cada etapa do gesto do caminhar eu investiguei não apenas articulações do pé e da perna, mas também os detalhes de todo o conjunto corporal, tal como os movimentos dos braços além da respiraçãoconcomitantemente implicados neste ato. Dito de outra maneira, cada gesto realizado com uma parte do corpo faz reverberar o movimento em todo o resto do corpo. A decomposição é um facilitador pedagógico de conscientização corporal.A mesma atenção que dei para os tornozelos e os joelhos também a dei para a cintura pélvica, a coluna vertebral, a cintura escapular, e os membros superiores, até finalmente chegarmos na cabeça. Sempre a trabalhar do movimento funcional para movimentos poeticamente expressivos (MERLEAU-PONTY, 2011).Até aqui descrevi parte do método de estudo para aquisição de acuidade corporal, que é a decomposição de movimentos. Eu trabalhei a sensibilização de início nas articulações ósseas e expandindo para a carne, para a pele e para meio ambiente exterior à pele. Vou agora explanar como trabalhei o ensino deste 
método aos cegos, e posteriormente descrever o processo inverso de sensibilização do meio ambiente até chegar aos ossos.

\subsection{Didática do Sensível}

No ensino da dança às pessoas cegas não é possível fazer demonstrações para contemplação visual de gestos e movimentos corporais. Para que eles sentissem o que era necessário trabalhar eu tocava com a mão nas suas articulaçõesos auxiliando no movimento desejado. Então Ihes pedia para perceberem o movimento realizado com o meu auxilio. E na sequencia solicitava que experimentassem o movimento por si mesmos. Experimentaram a flexão e extensão, a adução e abdução, a rotação e a circundução de cada articulação do corpo. Essa experiência se dava com as pessoas deitadas com as costasapoiadas no chão, com as pernas semi-flexionadas e pés apoiados no solo. A escolha de iniciar o experimento com as pessoas deitadas no chão se deu porque nesta posição era eliminada a força que o corpo exerceria contra a gravidade quando a pessoa está de pé. Além disso eliminaria também o peso do corpo sobre os pés, para queos pés estivessem livres de trabalhar enquanto objeto de sustentação.

Mas chamo atenção aqui para salientar que ainda o que estou descrevendo se trata dos estudos de movimentos funcionais.Em continuidade com a exploração didática na decomposição de movimentos, estudantes e eu passávamos por todas as articulações, doaté a cabeça.

Com uma mão apoiada na barra eu pedia aos estudantes que sentissem em deslocamento o gesto do caminhar com todas as articulações do pé envolvidas no estudo precedente, quando eles estavam deitados. Uma vez trabalhada a sensibilização das articulações deste gesto, nós passávamos a sentir o impulso dos artelhos para o salto. Primeiramente tocando os pés de estudantes para eles executarem posteriormente o gesto sem o meu auxilio. Depois cada estudante realizava o gesto do salto em um pé intercalado com o outro, mas com a mão sempre apoiada sobre a barra. $\mathrm{Na}$ sequência executavam o gesto em deslocamento ainda segurando na barra. No momento em que se 
sentiam seguros nós delimitávamos em conjunto um espaço onde eles saltariam livremente.

Uma vez que nós já tínhamos reaprendido de forma sensível sobre todas as possibilidades funcionais das articulações localizadas no corpo, eu dei sequência ao trabalho com o estudo dos movimentos expressivos. Para focar a atençãona expressividade dos pés, eu usei objetos como uma cortina a fim de cobrir todo o corpo e mostrar ao expectador apenas os pés. Mesmo com os estudantes cegos foi preciso o uso deste signo ou sinal da percepção: a sensação da pessoa estar de corpo todo coberto com a exceção dos pés.

A ideia de cobrir o corpo com uma cortina me surgiu pela necessidade de conduzir estudantes ao entendimento de que era desnecessário mover o resto de todo corpo durante a atividade expressiva dos pés. É muito comum até mesmo dançarinos experientes fazeremdos pés, suporte e objeto "utilitários" de deslocamento do corpo. Quando digo "utilitários" eu me refiro à situação literal e não metafórica em que os pés são destinados a permanecer como peça funcional do corpo. Ou seja quando artistas se servem dos pés somente como apoio enquanto o corpo dança, e não como expressão poética.

Foi portanto do meu interesse didático propor os pés como organismo dançante. Quando nós focamos nossa atenção nos pés, descobrimos outras possibilidades de combinação articular diferentes do cotidiano. Quando nós vivemos essas experiências, aprendemos que os pés se compõem organicamente com a totalidade do corpo expressivo.

A ideia de expressar as partes isoladas do corpo me surgiu da necessidade de ensinar estudantes a serem os mestres de si mesmos. Por meio deste estudo sensível estudantes tiveram acesso ao conhecimento do mecanismo articular e motor do próprio corpo. Puderam sentir minuciosamente seus movimentos, e colocarem estudos de cinesiologia, anatomia e biomecânica na memória e consciência de sua própria carne. Construíram autonomia para se expressarem poeticamente.

O acesso a esse conhecimento é fundamental para a dança, pois é 
parte da acuidade corporal. Precisarei ainda esclarecer mais adiante que a acuidade corporal se completa com todo o estudo que ainda estou explicando aqui.Ressalto que o estímulo tátil da percepção sensível ou sensorial que eu acabo de relatar, teve como princípio perceber os movimentos articulares dos ossos. Estes se propagam em direção à carne, e daí por diante para o corpo todo até o ambiente como exprimiu Gil (2009).

\subsection{Estudo baseado Lygia Clark}

Paralelamente ao que foi descrito até aqui eu também trabalhei com o estímulo sensível no sentido inverso: começando no ambiente em direção à interioridade corporal. Para esta abordagem eu me fundamentei com princípios propostos por Lygia Clark. Coellier, (2003) descreveu comoClark propôs desvelar o sensível através da relação entre corpo e esculturashabitáveis. O que eu chamo de esculturas habitáveis são as peças para serem manipuladas, vestidas ou incorporadas como: "Pedra de Ar", 1966; (COELLIER, 2003:23)"O eu e o tu: série roupa-corpo-roupa" (COELLIER, 2003:25), 1967; "Mascaras sensoriais”, 1967(COELLIER, 2003:26); “Mascara abismo”, 1968(COELLIER, 2003:28); “Arquiteturas biológicas: Ovo-mortalha”, 1968(COELLIER, 2003:29); dentre outras obras de sua autoria. Eu não construí esculturas habitáveis para os experimentos de pesquisa estética que compartilhei com os estudantes. Apenasempreguei o conceito de sua abordagem para habitara riqueza do ambiente em que a escola para cegos se encontra. Nele tínhamos arvores, flores, areias, grama, terra, etc. com diversas texturas, perfumes, sons e temperaturas que poderíamos pesquisar como estímulos sensorial.

Clark defendeu que a sensação emerge da própria carne, do contato da carne com um objeto, ou da carne com ela mesma.Segundo Coellier (2003) oque Clark buscou em suas proposições foi a sensação primária sem ativação das possibilidades de interpretação, que são mediadas pela consciência de memórias e recordações. Como tais seus eventos estão deslocados do aqui e do agora lá no passado. Clark se interessava pela sensação imediata do instante, sem passar para reflexões do que emerge do sensível. Ou seja sem 
uma engenharia de conceitos e através da bricolagem de perceptos.

Assim propus aos estudantes o estabelecimento de contato com diversos objetos encontrados na natureza. Por exemplo caminhar descalço. Ou rolar sobre um gramado com as pontas agudas ou cortadas, por vezes molhado ou aquecido pelo sol, ou ainda esfriado pela sombra, etc. Em outra ocasiões eu Ihes propus de tocar na areia com todo o corpo, e sentir se a areia era grossa ou fina, molhada ou seca, fria ou quente, etc. Ou ainda tocar o tronco das árvores, umas com texturas mais lisas e outras com relevos mais pronunciados. Ou ainda a fim de desenvolver a propriocepção, passar entre os fios de umacerca de arames farpados sem tocar a pele nas extremidades pontiagudas. A intenção foi desenvolver a potencialidade técnica e sensível do corpocom relação à si mesmo e à percepção do ambiente. Tudo isso sem buscar o que essas sensações provocariam na memória ou mesmo na imaginação. Ao invés disso a proposta era viver a própria sensação naquele momento experiencial,aquilo que ela provoca corporalmente sem referências prévias e sem as censuras de algo idealizado.

Para aguçar a sensibilidade aos sabores fizemos experiências gastronômicas. Por método eu sugeri a degustação de diversos sabores a serem experimentados isoladamente antes de combinados, tais como o amargo, o ácido, o doce, o salgado e outros. Para o estímulo do olfato eu dei prioridade aos cheiros que poderíamos sentir do meio ambiente, como por exemplo diferentes perfumes de flores do jardim, da grama, da terra ou da areia, molhadas ou secas. Às vezes propunha simplesmente sentir o perfume que se emanava após uma chuva. Também trabalhamos com alguns perfumes da indústria química. Trabalhamos além disso diferentes sons, inclusive a escuta do silencioque no final das contas não se trata de silencio, pois nosso corpo faz muito barulho. As aulas sempre começavam e finalizavam com uma pausa de reorganização corporal por meditação.

Esta pesquisa baseada em Clark teve como objetivo o desenvolvimento da sensibilidade do corpo no ambiente. Usei objetos externos ao corpocomo 
estímulo para a percepção do corpo no mundo. Os estímulos se iniciavam no ambiente, tocavam e ultrapassavam a fronteira da pele, para adentrar a carne, e atingir os ossos. Uma vez que a percepção sensível do corpoinspirada em Clark, foi encarnada nós passamos para a etapa seguinte inspirada em Laban, que foi das sensações corporais do peso/força, da fluência, do tempo e do espaço.

Até aqui descrevi como despertar a acuidade corporal, primeiro do interior profundo do corpo, para o ambiente e depois inversamente do exterior ambiental para o corpo. É muito difícil para não dizer impossível, tratar as coisas de forma estanque. Considero como Merleau-Ponty (1996) que é o próprio corpo por si mesmo quem habita o espaço ou ambiente sociocultural. Isso significa dizer que o sujeito é atuante no espaço, e não tem como se distanciar para fora de si e olhar-se a si mesmo como espectador de sua vida no mundo. Didaticamente é plausível focar a atenção de estudantes em tarefas separadas em partes, embora isso possa aqui na leitura deste artigo dar a falsa ideia de uma separação que não existe. No próximo item explicarei como foi o trabalho estético do corpo no espaço.

\subsection{Laban: As sensações corporais do peso/força, da fluência, do tempo e do espaço.}

Embora eu já tenha antes estudado Laban na minha graduação em dança na Sorbonne, minha principal mestra nessa disciplina foi a coreógrafa Lenora Lobo. Foi com ela que de fato aprendi sobre a ideia Labaniana e com ela compreendi melhores possibilidades de aplicação nas minhas pesquisas corporais. Lobo realizou seus estudos diretamente no Laban Center em Londres e ao chegar da Inglaterra especificamente em Brasília, coincidiu com meu retorno da graduação em dança e estudos somáticos. Em 1992 nós duas começamos a trabalhar juntas eainda mantemos nossa parceria.

Vou agora descrever a nova etapa do estudo para a aquisição da acuidade corporal, e esta se refere à percepção da pessoa no espaço. Ou seja a relação que estabelece o corpo com o seu ambiente externo. Para isto eu tive 
como base os fatores de qualidade de movimento propostos por Laban (1966, 2003 e 1988, 1994); (LOUPPE, 1997, 2004); (LOBO e NAVAS, 2003). Neste sentido passei a estudar primeiramente o peso/força, seguido pela fluência, depois o tempo e finalmente o espaço, para concluirmos com a percepção total do corpo no espaço.

Mesmo depois com estudantes que enxergam, procurei garantias para que este modo de aprendizado fosse conquistado a partir da experiência sensível. A ação principal aqui era cada pessoa se sentir a si mesma, isto é sentir o corpo e como ele se situa no espaço. Saliento que os estudantes experimentavam as direções, planos e eixos do corpo,a encarná-los para o seu aprendizado da acuidade corporal. É recorrente que exista muita dificuldade com a apropriação dançante deste conhecimento, porque estudantes não conseguem trazer seu conhecimento sensível da exposição do plano teórico para a praxis.

O primeiro fator estudado foi o peso/força. O seu estudo demandou necessariamente o trabalho dos três níveis de posicionamento do corpo com relação ao espaço. Entenda-se o alto, o médio e o baixo com ralação ao solo e à posição da pessoaem pé. Isto nos permitiu a consciência sensível da força exercida pelo corpo para erguer-se no solo. Quando deixávamos de resistir contra a gravidade, sentíamos ao mesmo tempo opeso corporal. Assim iniciamos o trabalho saindo do solo, do nível mais baixo ao mais alto, e depois em vice versa do alto para o baixo.

Como na posição em pé nós resistimos o tempo todo à gravidade, eu solicitei que os estudantes se deitassem ao solo para trabalhar a sensação de peso/força de membros isolados tal como por exemplo erguer somente o antebraço. O movimento realizadoisoladamente e em lentidãofacilita a percepção do peso do antebraço ou de qualquer outra parte do corpo. Quanto maior é o peso, mais força muscular será empregada contra a gravidade. Passei pelos diversos segmentos corporais, a sentir cada parte até uma conclusão da vivenciatotal do corpo sobre esses fatores do peso e da força.

Após experimentar o peso existente nas partes isoladas e a força em- 
pregada para ergue-las, solicitei que se levantassem lentamente para sentir diversos percursos de movimento corporal até a chegada de uma posição mais alta.Este foi o momento em que se fez necessário maior contração muscular para que o peso do corpo resistisse àgravidade. Uma vez de pé os estudantestambém experimentaram o caminho inverso (de cima para baixo). De todo este conjunto de experiências nós buscamos o conhecimento de qual é o peso do corpo que sustentamos e a força que fazemos para não desabarmos ao chão.

O trabalho realizado pelos três níveis supracitadosressalta a dificuldade que os estudantes apresentam em controlar a fluência de seus movimentos. Esse é um problema de percepção corporal que só se soluciona com a experimentação. Por isso mesmo a noção de fluência controlada é o fator que sempre proponho para estudar na sequência do conteúdo peso/força. O conceito de fluência livre é mais familiar sobretudo aos dançarinos. Dificilmente alguém nunca vivenciou a fluência livre ao menos quando era criança. Por isso optei por iniciar o estudo da fluência pela sua experimentação controlada e somente depois os estudantes experimentarem a fluência livre.

Para que os estudantes pudessem sentir na carne a fluência eu propus o seguinte exercício de iniciação. Pedi que deitassem sobre o solo em completa entrega a sentir todo o peso do corpo no chão. A partir desse estado de entrega, pedi que iniciassem um rolamento muito lento. Depois pedi que deitassem um ao lado do outro com o intervalo de um corpo no espaço vazio entre duas pessoas. Eles tinham que rolar até o final da sala sem atropelar o que estava a sua frente, e mantendo a distância inicial. Isto era um trabalho mais que tátil, tinha muito de escuta. Sublinho aqui em revisão que a escuta está nesta didática, desde o primeiro momento do trabalho na etapa de experimentação da interioridade corporal. Agora estávamos no momento da escuta relacional, além é claro da escuta corporal.

Quando os estudantes chegavam rolando ao final da sala de aula, se levantavam lentamente e se dirigiam pela lateral, para a outra extremidade da sala a sentir o equilíbrio e o desequilíbrio do corpo na ação de caminhar sem 
cair. Deviam manter sempre o ritmo lento e conservar a distância inicial entre os corpos. A proposta da manutenção da distância foi importante para que o trabalho do conjunto prevalecesse ao individual. Ao chegar de volta ao ponto inicial do exercício na extremidade da sala de aula, caminhando lentamente, os estudantes se deitavam outra vez sem atropelos, e assim era iniciadanovamente outra série de rolamentos. Não quero dizer com isso que funcionou desde a primeira experimentação, aqui foram necessárias algumas repetições. Mas a medida que cada estudante escutava a si mesmo, bem como ao ambiente, a harmonia de movimentos se instalava corporalmente. Eles apreciaram a fluência controlada com propriedade experimental. A condição deste trabalho demandaconcentração. Eu sempre disse aos estudantes que estudar dança requer a mesma atenção que damos à leitura de um livro. Ninguém lê um romance, estuda filosofia, matemática, ou qualquer disciplina que seja, ao mesmo tempo que dialoga com outra pessoa ou se distrai com qualquer coisa.

Uma vez que o fator fluência foi encarnado nós passamos à experiência decontrole sobre o tempo rápido ou lento, e sobre a direção de deslocamento de um ponto $\mathrm{A}$ até um ponto B. Experimentamos estes deslocamentos andando mais rápido, mais lento, correndo, em curva, linhas retas, e diversas outras posições e níveis. Todos esses fatores deveriam ser sentidos, e percebidos pela carne. Uma vez que este conhecimento estava encarnado eu passei a trabalhar o fator espaço: como quem dança se situa em cena, e como esta pessoa se move neste espaço de direções e eixos, qual a relação que ela tem com outras pessoase/ou objetos que compartilham do mesmo espaço. Dito de outra maneira:como o dançarino aguça sua escuta corporal para perceber onde ele se encontra e o que está a sua volta. Isso concluiu o estudo para a aquisição de acuidade corporal.

É importante esclarecer que o trabalho de Laban é muito mais abrangente do que o recorte por mim feito na minha pesquisa metodológica de ensino. Não foi o objetivo deste artigo descrever a ideia Labaniana em sua integralidade. Apenas menciono como parte de suas investigações foram integradas na minha pesquisa conjuntamente com o estudo de outros 
pesquisadores.

Tudo aquilo que era experimentado em ação edepois também era amplamente discutido com os estudantes em sala de aula, teve por finalidade o estímulo da reflexão estética sobre o aprendizado em expressão poética do corpo. Especialmente para relacionar o objetivo da aquisição de acuidade corporalno estudo da dança, visto que muitos entendiam o ensino da dança da forma tradicional: através de um professor que determina os gestos que os estudantes vão executar.

Foi difícil desempenhar esse trabalho porque naquela época eu tinha concluído apenas minhas graduações. Não tive uma orientação de pesquisa nem um grupo de estudo, onde eu pudesse tirar minhas dúvidas e compartilhar minhas pesquisas, angustias e resultados. Fiz tudo sozinha, com a participação e colaboração dos estudantes. Mas não me percebia no desempenho de uma pesquisa teórica em estética e pedagogia da arte, e nem se quer desenvolvendo uma proposta metodológica em dança. Nessas condições foi impossível registrar dados. Isso só ficou claro para mim muito tempo depois. Na época eu só me preocupava em achar uma maneira de ensinar pessoas cegas a dançar. Eu acreditava e ainda acredito que o ensino das artes nas escolas deva ser pelo desempenho das autonomias poética e crítica de cada pessoa.

Havia um certo receio por parte dos estudantes para mostrarem que sabiam dançar. Eles precisavam conhecer resultados para se sentirem capazes, visto que ao longo de nossas vidas nós somos constrangidos pela observação alheia. Desta forma o olhar sobre si mesmo é um equilíbrio constante da nossaautoafirmação face ao olhar de outras pessoas sobre nós. Procuramos ser percebidos como semelhantes ou até mesmo como diferentes, entendido que a percepção da existência dos outros confirmaa nossa própria existência. O olhar do outro nos constrói, nos interroga sobre nós mesmos, e nos reenvia um eterno reflexo. Segundo Sartre $(1943,1985)$ nós todos precisamos de ser reconhecidos pelos outros para existir. Após a conclusão deste estudopara a aquisição de acuidade corporal em dança,nós passamos para outra 
etapa em direção ao compromisso de apresentar ao público nossa composição coreográfica.

\section{A PESQUISA COREOGRÁFICA}

Desde o início eu sabia que tinha diante de mim um desejo e uma certa ansiedade por parte dos estudantes em fazer uma apresentação coreográfica, talvez para provarem-se a si mesmos bem como aos seus entes próximos que eram sim capazes de dançar. Eu também queria apresentar parte do resultado desse trabalho que me foi tão caro. O que eu nunca quis me propor foi de fazer foco em apresentações apenas para datas festivas. Fazer arte é produzir conhecimento.Então para iniciar a pesquisa coreográfica com os estudantes cegos, eu me inspirei na proposta que havia aprendido durante a minha graduação em dança, tal como já foi dito ao longo desse artigo. No nosso trabalho as autonomias poética e crítica foram valorizadas durante o processo colaborativo entre professora e estudantes. Os dançarinos tiveram autoridade nas suas propostas, à maneira do exemplo de Pina Bausch que foi pioneira na estética ocidental da dança, porque desconstruía a autoridade quase ditatorial de coreógrafos.

O tema que nesta etapa pesquisei em colaboração com os estudantes cegos foi sobre a sensação do movimento corporal na água. Buscamos na memória a sensação que guardávamos dessa condição ambiental. Para garantir que os estudantes tivessem de fato essa memória encarnada, eu fiz com que nós tivéssemos diversas experiências dentro d'água.Para a criação estética dentro desta proposta em arte coreográfica e dança contemporânea, as imagens (táteis, olfativas, auditivas, etc.) são percebidas e restituídas de outra maneira. Não temos como congelar imagens da memória a fim de reproduzi-las tal qual foram percebidas no passado, mas podemos pelo menos falar de reapropriação simbólica das coisas.Para a expressão artística em dança contemporânea tratada aqui, o dançarino está livre para fazer visível através do movimento corporal em cena a sua própria percepção de mundo. O próprio corpo 
dançante é a obra de arte do dançarino. A pessoa acede através da arte coreográfica à transformação da carne-do-cotidiano em corpo-obra-de-arte. A pessoa que dança faz com que seus movimentos ganhem um sentido poético para ele mesmo. Ela é um poeta do corpo.

A pessoa dançante é um composto do seu corpo biológico acrescido de todos afetos que ela experimenta culturalmente, e que traz encarnados na própria pele através da vida social. Ela vive sua experiência sensorial, emocional, intelectual, e espiritual, onde o corpo produz os afetos que se desvelam na dança sob a forma de movimento. Por isso quem faz arte é agente de conhecimento, agente da história e da cultura na sociedade. Entre artistas enquanto agentes culturais eu considero que quem dança, deve possuir acuidade corporal para expressar com exímia técnica sua poesia, independentemente do conceito de estética em questão na obra de arte. Isso significa não deixar aprópria vaidade submergir em uma catarse idiossincrática das próprias emoções. Ao contrário a pessoa que dança deve saber como expressar suas emoções mais efêmeras e menos dramáticas, tornando-as visíveis por meio de movimentos poéticos e críticos, sem a tentativa de traduzir seus sentimentos e questões da própria existência por gestos literais. Ou seja movimentos criativos e reflexivos que sensibilizam o olhar por sua plasticidade instalada, e que provocam reflexão no pensamentodas pessoas que contemplam a obra de arte, através de sua intervenção estética no mundo. Pois a proposta na arte coreográfica em dança contemporânea aqui sugerida não é interpretar sentimentos e sim expressar suas percepções de maneira poética e crítica.

Os movimentos subjacentes à imaginação são consequência da sobreposiçãona memória dos sentidos. Eles desenham na cena trajetóriasreveladoras do que se afeiçoa pela própria identidade pessoal de quem dança, para a observação de quem contempla a obra de arte. A meu ver quem dança não deve ser escravo de acessórios como por exemplo roupas, iluminação, cenário, música, etc. Nada impede nem obriga que quem dançautilize estes e outros acessórios. É através da corporeidade que uma pessoa será capaz de desvelar suas experiências de maneira poética à percepção de observadores. 
É importante combinar numerosas possibilidades de organização dos movimentos, pois quem dança é a matéria como diria Heidegger (2010), uma matéria plástica que compõe a coreografia. É necessário expressar lucidamente os gestos dançantes,e para isso é importante ter autoconhecimento somático. Isto é acuidade corporal.Para se compor uma coreografia nesta proposta pedagógica de criação, é preciso um sujeito de estudo que aporte certa inquietude, com a qual sendo artista deseja se envolver. A experiência vivida é muito importante para o desempenho da pesquisa de movimentos corporais. Pois é necessário que esta pesquisa de movimentos enquanto objeto de estudo estético se instale na carne.

Trabalhei com a memória para ativar as sensaçõesdos estudantes neste caso específico da composição coreográfica, diferentemente dos casos anteriores que descrevi aqui sobre estudos estéticos do interior e do ambiente para a acuidade corporal. Já foi mencionado anteriormente que eu comecei junto aos estudantes cegos por uma pesquisa de movimentos para a composição coreográfica, cujo objeto foi a sensação do corpo na água.Foi preciso tempo antes que a carne se afeiçoasse às novas experiências de reflexão e crítica do movimento (na água), e que esta experiência passasse a ser suficientemente habitual para que os estudantes trabalhassem poeticamente a situação vivida.

Através da imaginação é possível ter acesso a quase tudo, mesmo que as imagens pensadas não sejam tocáveis pelas mãos. Lembranças de imagens (táteis, auditivas, olfativas, etc.) são armazenadas na memória.Estas provocam nas pessoas sensações, tão logo Ihes sejam desveladas pela autoreflexão sobre si mesmas o agenciamento de um mundo em que cada qual ocupa seu respectivo lugar. Para tornar mais claro ao leitor eu tomo como exemplo algo acessível a todos: a lembrança de um beijo que provoca sensações muito intensas. Devo esclarecer aos leitores que esse específico exemplo não foi dado para estudantes menores de idade legal.

O beijo é um exemplo privilegiado porque a lembrança de semelhante 
sensação estimula o desejo e o prazer no imaginário. A partir da imaginação criam-se imagens, ícones e símbolos que são representações coletivas. Estas imagens da experiência de vida imaginadas em pensamento desencadeiam outras sensações físicas e metafísicas, sentidas na carne a partir deste estímulo provocado pela lembrança. Cada pessoa com sua característica particular pode exprimir sensações muito semelhantes como o beijo porém de maneiras bem distintas.Mesmo as pessoas envolvidas na mesma ação expressam a experiência de forma singular.

Seguindo a ideia deste exemplo aqui citado, a proposta para a expressividade não é a reprodução das ações simuladoras de um beijo. Mas sim a expressão com acuidade poética corporal da sensação que aporta a lembrança de um beijo. No entanto é importante sublinhar nesse trajeto para a expressividade coreográfica, que o que ocorre inicialmente durante a improvisação no momento em que se faz a pesquisa de movimentos, é o puro e simples impulso de movimentos, o que não é a mesma coisa de movimentos refletidos critica e poeticamente.Quando a pessoa que dança faz uma pesquisa para sua composiçãocoreográfica, ela não chega despida de seus afetos, com a carne vazia de experiência vivida. De tal maneira que ela não pode se desvencilhar de suas experiências, para propor um trabalho com as experiências de outra pessoa. A corporeidade não está despelada da intencionalidade encontrada originalmente no instante da criação coreográfica. Assim ocorrem sempre no início das pesquisas, movimentos que são produto de impulsos muitas vezes inconscientes. Mas se quem dança escolhe a simples reprodução ou exteriorização deste material bruto, isto não se trata de expressão entendida aqui por nós pelo conceito de corporeidade. Isso seria apenas imitação de gestos.Um ato expressivo para a criação em dança contemporânea não é jamais o resultado imediato de uma emoção qualquer.

Considero que a criação artística seja a realização da intencionalidade, uma vez que esta é resultado de uma reflexão compartilhada com a expressão corporalpensada para a composição coreográfica. A etapa da emoção pura pode se apresentar no momento da improvisação. Isso resulta no movimento 
que é realizado pela força da experiência sem a reflexão de um arranjo. Mas no entanto assim que quem dança seleciona seus movimentos em plena improvisação, estes já se transformam no resultado de um ato refletido semelhantemente ao improviso musical, cujo artista tem impressa a sua biografia na expressão de seu som.

A expressividade passa sempre pelos afetos entre pessoa e mundo. Axioma este de onde eu questiono o quanto afetos plásticos da vida cotidiana, podem ser vistos por um olhar esteticamente treinado para a observação de movimentos poéticos.Dewey (2005) argumentou que um poema, um quadro, uma escultura ou outra obra artística, representam um material filtrado pela experiência pessoal do artista. Ele entende que o material para a realização da obra artística é adquirido no mundo público. O artista, o material de composição, e a obra artística, todos compartilham qualidades em comum.Estasideias de Dewey são válidas também para a dança.

A dança remodela movimentos cotidianos, e os transforma em poesia. Quando atua em cena o dançarino é ele mesmo a matéria artística e o material da obra de arte (HEIDEGGER, 2010). Quando observamos o dançarino em cena, o que vemos é um corpo biológico carregado de seus afetos, transformado plasticamente a cada movimento expresso. O corpo não é utensílio de quem dança, não podendo ter caráter de objeto de uso, tal como também não podem as botasna obra de Van Gogh de acordo com a análise de Heidegger. A pessoa que dança é a matéria prima da arte coreográfica ao mesmo tempo em que também é a forma dada, para que estamesma matéria humana venha a ser obra de arte através da dança. A plasticidade escultural que desenha a forma no espaço é por ela mesma esculpida em movimentos. Esta reflexão é necessária para nós reafirmarmos a ideia que eu faço para o ensino da dança nas escolas, bem como o ensino das artes em geral. Acredito que este ensino tem como função colaborar para a formação de cidadãos críticos, não repetidores de ações padronizadas nem seguidores de doutrinas. Dentro desta proposta estética os estudantes cegos e eu trabalhamos a coreografia que foi apresentada no final do ano letivo de 1994. Os estudantes que participaram do 
processo de pesquisa para a coreografia foram jovens de 5 a 15 anos. Estudantes adultos não se sentiram a vontade em participar de uma pesquisa estética, e se recusaram à experiência do processo de aprendizagem da acuidade corporal. Eles se preservaram nacrença sobre aquilo que aprenderam de certa (ou errada) forma,o que deveria ser dança. Eles entendiam que para dançar era necessário a cópia de movimentos formatados. Enquanto eu propunha a autonomia poética da pessoa que danç.

Paralelamente a esta experiência com estudantes cegos eu também trabalhei com profissionais da dança, aplicando com estes os mesmos princípios metodológicos de pesquisa estética que realizei junto aos estudantes da rede pública de ensino do DF. Posteriormente fui ensinar na Universidade de Brasília - UnB . Nunca mais voltei a ter contato com estudantes de ensino fundamental e médio e nem com esta ou outra especialidade. Contudo eu orientei um Trabalho de Conclusão de Cursode graduação em dança do Instituto Federal de Brasília - IFB - em 2012, cujo tema foi a aplicabilidade dessa proposta metodológica em estudantes do ensino fundamental em uma escola da rede pública do Distrito Federal.

\section{RESULTADOS}

Esta pesquisa resultou em uma proposta metodológica que foi primeiramente experimentada em mim mesma. Depois foi aplicada junto aos estudantes cegos assim como profissionais da dança. Foi também ministrada no curso de teatro da Universidade de Brasília - UnB, entre 1996 e 2005. Ensinei também a estudantes de dança da Universidade Paris 8, entre 2006 e 2009; aos estudantes de dança do Instituto Federal de Brasília, IFB, entre 2010 e 2013 e aos estudantes do Departamento de Dança da Universidade do Québec em Montréal, UQAM entre 2013 e 2015.

\section{CONCLUSÃO}

Nesta metodologia o processo de pesquisa estética auxilia na compreensão e 
encarnação de estudos cinesiológico, anatômico e biomecânico aplicados à dança. Mas sobretudo o método colabora para nos entendermos que o aprendizado da dançabem como de outras artes é reflexivo. Trata-se da encarnação do estudo soma-estético $($ soma $=$ corpo, estético $=$ reflexivo). A dança é uma modalidade artística dentre tantas outras que além disto é múltipla em si mesma (ballet clássico, jazz, dança contemporânea, etc.). Portanto visa a expressão e não o condicionamento físico do estudante que é uma consequência da prática. Considero que o ensino e o aprendizado da dança deveria ser sempre mais orgânico e menos mecânico.Além disso essa metodologia colabora para acompreensão da individualidade corporal, bem como coloca o sujeito pronto para o trabalho em grupo. Uma vez que a pessoa se escuta, fica mais fácil escutar o coletivo. Outro ponto relevante desta proposta é que ela colabora para as autonomias crítica e poética de quem dança. Colabora também com a integração de pessoas especiais, desenvolvendo acuidade corporal. A intenção é de que a partir dessa proposta qualquer pessoa desenvolva a sua própria habilidade para trabalhar a dança. Não se trata de um modelo fechado e concluído, a ser repetido como em uma receita. Proponho apenas que cada pessoa desenvolva à sua própria maneira,um de trabalho coreográfico e de ensino da dança a partir dessas ideias.

\section{REFERÊNCIA BIBLIOGRAFICA}

BATSON, Glenna. L'éducationsomatiquedanslemilieu de ladanse.Publicadopela "International Association for Dance Medicine and Science (IADMS).", 2010.

BELLMER, Hans. Petiteanatomie de l'image ou l'anatomie de l'image, Paris,editora Allia, 2006.

BOURDIEU, Pierre. Habitus, code et codification. In: Actes de la recherche en sciences sociales. Vol. 64, septembre 1986. De queldroit ?pp. 40-44. http:// www.persee.fr/doc/arss 0335-5322_1986 num_64_1_2335

COELLIER, Sylvie. Lygia Clark (L'enveloppe): La fin de lamodernité et ledésirducontact. Paris, edititora de l'Harmattan, 2003.

DEWEY, John. L'artcommeexpérience.Pau, edição Farrago, 2005.

ENDICOTT, Jo Ann.Je suis une femmerespectable. Paris, editora L'Arche,1999. 
GIL, José. Movimento total, o corpo e a dança. Rio de Janeiro, editoralluminuras, 2009.

GODARD, Hubert. Le gestemanquant.Entrevista com Daniel Dobbels et Claude Rabant, in IO, revueinternationale de psychanalyse, $n^{\circ} 5$, 1994, p 63-75.

HEIDEGGER, Martin. A origem da Obra de Arte. São Paulo, Edições 70, 2010

LABAN, Rudolf. Espace Dynamique. Bruxelas, editora Nouvelles de Danse, (1966), 2003.

2003.

La maîtrisedumouvement.Bruxelas, editora Nouvelles de Danse,

LÉVI-STRAUSS, Claude.La pensésauvage .Paris, editora Pocket, collection Agora, (1962, Plon),2010.

LOBO, L. e NAVAS, C. Teatro do Movimento, um método para o intérprete criador. Brasília, editora L.G.E, 2003.

LOUPPE, Laurance. Poétique de ladansecontemporaine. Bruxelles, Editora Contradanse (1997), 2004.

MAUSS, Marcel. Les techniques du corps (1934).Artigo originalmente publicado no Journal de Psychologie, XXXII, - 15 de abril de 1936. Comunicação apresentada na Société de Psychologiele 17 mai 1934.

MERLEAU-PONTY, Maurice. Senset non sens. Paris,ediçãoGallimard, (1966), 1996. mard, coleção Tel, (1945), 1996.

Phénoménologiede la perception. Paris, editora Galli-

Le Monde Sensible et le Monde de l'Expression. Curso no Collège de France, 1953. Genebra, editora MetisPresses, 2011.

MICHEL HENRY. Philosophieetphénoménologie du corps (1965). Paris, editora PUF, Épiméthée, 2006.

SARTRE, Jean-Paul. L'êtreet le néant.Paris, editoraGallimard, (1943) 1985.

SERVOS, Norbert.Pina Bausch oul'Art de dresser unpoisson rouge. Paris, editoral'Arche, 2001

SHUSTERMAN Richard. Conscience du corps, pour une soma-esthétique. Paris, editora l'éclat, 2007.

SHUSTERMAN Richard. Penser en corps.Eduquer les sciences humaines: unappel pour la soma-esthétique.Paris, editora L'Harmattan, 2009. 